\title{
Editorial: Natural Hazards Engineering Research Infrastructure (NHERI): Mitigating the Impact of Natural Hazards on Civil Infrastructure and Communities
}

\author{
Arindam Chowdhury ${ }^{1}$, Joel Conte ${ }^{2}$, Forrest Masters ${ }^{3}$, Julio Ramirez ${ }^{4 \star}$ and James Ricles ${ }^{5}$ \\ ${ }^{1}$ Florida International University, Miami, FL, United States, ${ }^{2}$ University of California at San Diego, La Jolla, CA, United States, \\ ${ }^{3}$ University of Florida, Gainesville, FL, United States, ${ }^{4}$ Purdue University, West Lafayette, IN, United States, ${ }^{5}$ Lehigh University, \\ Bethlehem, PA, United States
}

Keywords: storm surge, tsunami, earthquakes, windstorms, research infrastructures

\section{Editorial on the Research Topic}

Natural Hazards Engineering Research Infrastructure (NHERI): Mitigating the Impact of Natural Hazards on Civil Infrastructure and Communities

\section{OPEN ACCESS}

Edited and reviewed by: Gregory A Kopp,

Western University, Canada

${ }^{*}$ Correspondence: Julio Ramirez ramirez@purdue.edu

Specialty section: This article was submitted to Wind Engineering and Science,

a section of the journal

Frontiers in Built Environment

Received: 12 May 2021 Accepted: 03 June 2021 Published: 15 June 2021

Citation: Chowdhury A, Conte J, Masters F, Ramirez J and Ricles J (2021) Editorial: Natural Hazards Engineering Research Infrastructure (NHERI): Mitigating the Impact of Natural Hazards on Civil Infrastructure and Communities. Front. Built Environ. 7:708450. doi: 10.3389/fbuil.2021.708450
Natural hazards in the form of earthquakes, windstorms, and associated events such as tsunami and storm surge can devastate a community's civil infrastructure and severely disrupt the broader society. Communities can take years to recover from widespread damage to, or failures of, civil infrastructure. This is evident from the experiences of the Indian Ocean tsunamis, the Canterbury earthquake sequence in New Zealand, the Tohoku tsunami in Japan, and Hurricanes Katrina, Ike, Sandy, Harvey, and Maria in the United States. With a multi-disciplinary and coordinated research effort, however, it is possible to mitigate costly impacts of natural hazards-and prevent them from becoming societal disasters. Illustrations of the devastation caused by some of these natural hazard events are shown in Figure 1 (left - Hurricane Ike and right - Haiti earthquake).

The Natural Hazards Engineering Research Infrastructure (NHERI) is a shared-use, nationally distributed network that provides key infrastructure for the natural hazards engineering and social science community. NHERI combines state-of-the-art experimental facilities with a computational modeling and simulation center, a convergence-science hub, and post-event reconnaissance and research teams. NHERI's coordination office leads education and community outreach, supports research operations, and manages governance to provide fair and clear access. In addition, NHERI provides a cyberinfrastructure for research and collaboration. NHERI is funded by the National Science Foundation (NSF). The community of NHERI researchers, educators, and students encompasses a large group of universities, industry and federal partners, and research institutions in the United States and abroad.

The research topics covered in the special issue pertain to the unique capabilities of the twelve NHERI components, as well as user satisfaction measures collected by the NHERI User Forum, and examples of community-organized, post-event reconnaissance. Together, the fifteen papers in this collection illustrate the strength and effectiveness of a community of researchers empowered by shared-use facilities and components that encourage multi- and interdisciplinary collaboration. The contributions also highlight how open access to data and high-performance computing resources can advance the state of knowledge. Further, by cutting 


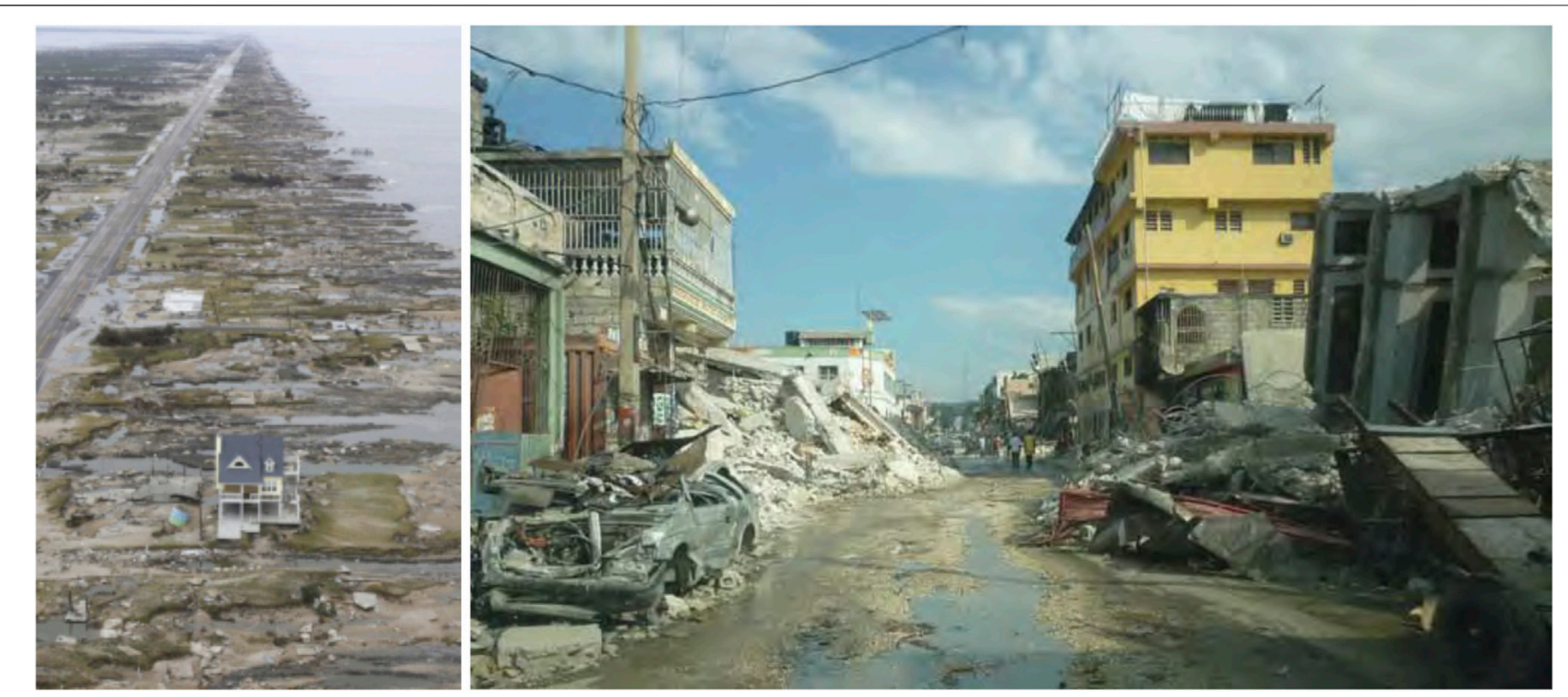

FIGURE 1 | Bolivar Island, TX, after Hurricane Ike, 2008 (left) and Port au Prince, Haiti, after 2010 earthquake (courtesy of or with permission of M. Eberhard, University of Washington, Seattle, WA, United States) (right).

across disciplinary borders and advancing convergence science to solve grand challenges, NHERI efforts show that it is possible to improve community resilience against the impact of natural hazards. The articles in this collection point to the enabling impact made possible by researchers, students, educators, and practitioners collaborating within the NHERI network.

The NHERI community has fostered the development of students - the earthquake, wind, and coastal engineering researchers of the future. As well, it has provided useful resources for practicing engineers and social science researchers. Since its inception in 2015, NHERI efforts have resulted in a wealth of invaluable experimental data, which are crucial to develop, calibrate and validate high-fidelity computational models of civil infrastructure systems. The community will continue to produce transformational research and outcomes that influence engineering and, increasingly, inform interdisciplinary practice by way of computational simulation models to design guidelines and codes.

\section{AUTHOR CONTRIBUTIONS}

All authors listed have made a substantial, direct, and intellectual contribution to the work and approved it for publication.

Conflict of Interest: The authors declare that the research was conducted in the absence of any commercial or financial relationships that could be construed as a potential conflict of interest.

Copyright (c) 2021 Chowdhury, Conte, Masters, Ramirez and Ricles. This is an openaccess article distributed under the terms of the Creative Commons Attribution License (CC BY). The use, distribution or reproduction in other forums is permitted, provided the original author(s) and the copyright owner(s) are credited and that the original publication in this journal is cited, in accordance with accepted academic practice. No use, distribution or reproduction is permitted which does not comply with these terms. 